TI 2015-109/V

Tinbergen Institute Discussion Paper

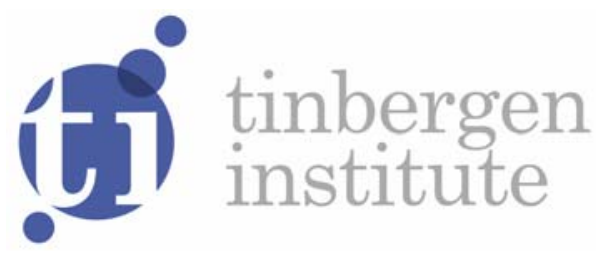

\title{
Employee Health and Employer Incentives
}

\author{
Patrick Hullegie \\ Pierre Koning
}

Faculty of Economics and Business Administration, VU University Amsterdam, and Tinbergen Institute, the Netherlands. 
Tinbergen Institute is the graduate school and research institute in economics of Erasmus University Rotterdam, the University of Amsterdam and VU University Amsterdam.

More TI discussion papers can be downloaded at http://www.tinbergen.nl

Tinbergen Institute has two locations:

Tinbergen Institute Amsterdam

Gustav Mahlerplein 117

1082 MS Amsterdam

The Netherlands

Tel.: +31(0)20525 1600

Tinbergen Institute Rotterdam

Burg. Oudlaan 50

3062 PA Rotterdam

The Netherlands

Tel.: +31(0)10 4088900

Fax: +31(0)10 4089031 


\title{
Employee Health and Employer Incentives*
}

\author{
Patrick Hullegie \\ VU University Amsterdam and Tinbergen Institute \\ and \\ Pierre Koning \\ VU University Amsterdam, Tinbergen Institute, and IZA
}

August 2015

\begin{abstract}
In the past two decades the OECD has regularly voiced concern about the labor market exclusion of people with disabilities and about the cost of disability insurance programs. This paper examines whether the fundamental disability insurance reforms that were implemented in the Netherlands have helped or hindered employment opportunities of workers with health problems or disability. An important component of the Dutch reforms was to enhance employer incentives, which was done by making them responsible for paying sickness benefits and by strengthening their sickness monitoring obligations. These employer incentives may stimulate preventive and reintegration activities by firms, thereby improving the employment opportunities of disabled workers. However, the reforms also impose substantial costs on employers when an employee gets sick and may therefore reduce employment opportunities of disabled workers. We use data from the Dutch Labor Force Survey and rich administrative data from hospital admission records, social security records, and the municipality registers containing demographic information to examine whether the disability reforms have in fact improved the economic situation for the disabled. On balance, we conclude that the DI reforms implemented by the Dutch government have mainly protected those who already have a job, and may have inadvertently reduced the hiring opportunities of people with a disability.
\end{abstract}

JEL Classification: H53, J14, J18

Keywords: disability insurance, employer incentives, policy evaluation

\footnotetext{
* We have benefitted from the opportunity to present this work at the 5th CAFE Workshop, the 11th World Congress of the Econometric Society, and in a seminar at the Erasmus School of Economics, Rotterdam.
} 


\section{Introduction}

In the past two decades the OECD has regularly voiced concern over the labor market position of people with disabilities and the cost of disability insurance (DI) programs (OECD, 1992, 2003, 2010). Improving the labor market position of people with disabilities is not only important for their own economic well-being, it is also considered essential in addressing the challenges that countries face regarding population aging (OECD, 2010). Recognizing the need for reform, many countries have implemented changes to their disability programs in the past two decades.

The objective of this paper is to examine whether the disability reforms that were implemented in the Netherlands have helped or hindered the employment opportunities of workers with health problems or disabilities. The Netherlands presents an interesting setting because the government fundamentally reformed its disability program. In the 1980s and 1990s the Dutch disability program was considered to be the most out-of-control disability program within the OECD, a status sometimes referred to as the "Dutch disease." ${ }^{1}$ To illustrate, in 1990 the Netherlands spent 4.7 percent of its GDP on disability insurance - which was 2.2 percentage points higher than Norway, the second biggest spender on disability insurance in the OECD and more than three times as large as the OECD average of 1.3 percent (OECD, 2010). Due to the reforms the disability program transformed from one that merely paid benefits to one in which employers play an important role in reintegrating disabled workers, and spending dropped to less than two percent of GDP in 2010.

An important component of the Dutch reforms was to enhance employer incentives, which was done by making them responsible for paying sickness benefits and by strengthening their sickness monitoring obligations. Especially the latter, as specified in the so-called "Gatekeeper protocol" enacted in April 2002, is widely considered to be the most effective DI reform in the Netherlands (see section 2 for more details). The rationale behind enhancing employer incentives was that they stimulate preventive and reintegration activities, and workplace accommodations for sick and disabled workers, thereby improving their labor market opportunities. However, as a consequence of the reforms employers are confronted with substantial costs when an employee

\footnotetext{
${ }^{1}$ The phrase "Dutch disease" originally referred to the way in which the manufacturing sector in the Netherlands was adversely affected by discoveries of natural gas in the late 1950s. Meanwhile, it has become an umbrella term for the problems faced by economies with high levels of energy or other natural resources. For labor economists it also refers to the sharp increase in disability rolls in the Netherlands between the 1960s and 1980s.
} 
gets sick. These costs are not only monetary, but also arise from increased monitoring obligations and the difficulty of terminating the contracts of workers with health problems or disability (OECD, 2010, p. 135). Hence, these reforms may have had the unintended consequence of lowering employment opportunities of workers with health problems or disability. Ultimately, it is an empirical question which of the two effects has dominated.

Whether the disability reforms have improved employment opportunities of disabled workers is an intrinsically difficult question to answer. The DI program is uniformly administered and the reforms covered the entire program, leaving no opportunities for treatment-control comparisons. Notwithstanding this difficulty, we present two complementary empirical strategies to shed light on the effects of the reforms. To begin, we present a descriptive analysis based on the Dutch Labor Force Survey (LFS) for 2000-2010. These data are useful for our purposes because the LFS identifies workers with health problems and workers with a disability. This allows us to investigate how the relative employment of these groups of workers has evolved over time. The LFS data suggest that the employment opportunities of ill men and women have improved over the sample period, and that the reforms may have had the most negative effect on the labor market position of disabled women.

We pursue a second empirical strategy to estimate the effects of the disability reforms in order to avoid identification from a self-reported health measure that is possibly endogenous to labor force status (Bound, 1991; Kreider, 1999) or affected by the reforms through changed (social) norms for reporting a disability. We use data from hospital admission records with universal population coverage to define a sudden deterioration of health (or "health shock") as an unscheduled hospital admission that requires immediate treatment. Hence, we utilize variation in health that is less prone to measurement error relative to self-reported health measures and arguably (more) exogenous to labor market status (see also García-Gómez, Van Kippersluis, O'Donnell, \& Van Doorslaer, 2013). We combine the hospital admission records with administrative data from several other sources, which together provide a population-level panel data set with information for every person about their demographic characteristics, health status and labor market outcomes. Using these data we investigate the difference between the response to a health shock in a year after the DI reforms were implemented and the response to a health shock in a year prior to the major DI reforms. We find that the labor market position of workers 
who experience a health shock has improved after the series of reforms: they are less likely to receive disability insurance benefits and they are more likely to remain employed.

Taken together, we conclude that the DI reforms implemented by the Dutch government have mainly protected those who already have a job, and may have inadvertently reduced the hiring opportunities of people with health problems or a disability. This conclusion is an useful input into discussion about the rapid growth of DI programs faced in many countries, and which poses significant financial risks to those programs. Our analysis shows that enhancing employer incentives might be a fruitful way to a more sustainable growth path of DI programs. See Autor and Duggan (2006) and Koning and Lindeboom (2015) for reviews of the literature on the causes and consequences of growing DI rolls, and what might be done about this.

This paper also contributes to a literature that evaluates policies that aim to improve labor market outcomes of people with disabilities. DeLeire (2000), Acemoglu and Angrist (2001), Beegle and Stock (2003), and Kruse and Schur (2003) examine the consequences of the 1990 Americans with Disabilities Act (ADA), which intends to ban discrimination and mandates "reasonable workplace accommodations." The ADA may therefore have expanded the employment opportunities of disabled people. The ADA, however, also increases the costs of employing disabled workers, which in turn may have harmed the employment opportunities of disabled workers. DeLeire (2000) and Acemoglu and Angrist (2001) find support for the latter possibility, by examining the time series of relative employment and relative wages of disabled people. Both papers find (large) negative effects on the employment opportunities of men with disabilities beginning in 1990, but no effects on wages of disabled men. However, two other papers challenge these findings, arguing that the ADA may have either helped or hurt employment of disabled people depending on the model specification (Beegle and Stock, 2003) or on the disability measure used (Kruse and Schur, 2003). ${ }^{2}$

While the ADA and the Dutch reforms are similar in the sense that both aim to incentivize employers to provide reasonable workplace accommodations to employees with disabilities,

\footnotetext{
${ }^{2}$ Disability discrimination laws in countries other than the U.S. have received little attention. Bell and Heitmueller (2009) find that the 1996 Disability Discrimination Act in Britain had no impact on the employment rate of people with disabilities. Besides anti-discrimination legislation, employment quotas are frequently used to improve employment among disabled workers. Lalive, Zweimüller, and Wuellrich (2013) analyze the effect of quotas in Austria and find that it promotes employment of disabled workers.
} 
there are also substantial differences. An important component of the ADA is the antidiscrimination legislation, whereas the Dutch laws impose responsibilities to employers that go considerably beyond those given by the ADA. Moreover, although the ADA requires employers to implement reasonable workplace accommodations, Autor (2011) argues that "this provision is vaguely defined and difficult to monitor or enforce." By contrast, in the Netherlands the Gatekeeper protocol enables the Social Security Administration to monitor and enforce (through sanctions) efforts made by the employer to reintegrate the disabled worker.

The remainder of this paper is organized as follows. Section 2 details the institutional context in the Netherlands. Section 3 discusses the descriptive analysis based on the Dutch Labor Force Survey. The analysis based on the administrative data is presented in section 4 . Finally, in section 5 we discuss how our findings may be useful for countries, such as the U.S., that face a rapid and unsustainable expansion of the DI beneficiary population.

\section{Institutional Context}

The provision of disability insurance in the Netherlands is mandatory and covers all employees against all income losses resulting from impairments that occurred on the job or elsewhere. Since 2004 workers apply for DI claims after a "waiting period" of two years of sickness. During this period, employers are responsible for the provision of reintegration activities and the continued payment of wages. Next, disability claims are assessed by the Social Security Administration (SSA). Disability benefits depend on the "degree of disability," which is defined as the percentage difference between prior earnings and the remaining potential earnings capacity.

There are three key differences between the disability programs in the Netherlands and the United States. First, unlike in the U.S., workers in the Netherlands may receive partial disability benefits. Hence, Dutch DI beneficiaries may simultaneously work and receive disability benefits. Second, disability benefits only depend on the "degree of disability" and not the number of dependents and/or work history. For fully disabled individuals, disability benefits provide insurance for 70 percent of the loss of income due to impairments. Third, health insurance coverage is universal in the Netherlands and not tied to DI receipt (or a person's job).

The Dutch disability program has been plagued by moral hazard problems in the past. To illustrate, figure 1 plots the fraction of the working-age population (age $20-65$ ) that receives DI benefits and the fraction that is newly awarded DI benefits for the period $1968-2010$. The 
fraction of the working-age population receiving DI benefits quickly rose from 2 percent in 1968 to about $7-8$ percent in the mid 1980 's, remained roughly constant at this unprecedented level for the next two decades, and started to decline at the beginning of the 21 st century.

One important institutional feature that gave leeway to the sharp rise in enrollment is that disability insurance includes all medical contingencies. Parsons (1991) argues that a broad definition of disability risks increases the likelihood of screening errors into disability determinations. As it seems, applicants successfully exploited this feature of the Dutch DI system, with the Social Security Administration prioritizing on minimizing erroneous denials (Burkhauser, Daly, \& De Jong, 2008). In addition, moral hazard effects were aggravated by sickness benefits that fully replaced wages during the waiting period. As such, incentives to resume work quickly were limited.

Although a continuous need for reform in the DI system was felt since the Eighties, it took until 2002 to attain substantial decreases in the inflow rate. Prior to 2002, policy changes aimed at increasing the financial incentives for employers to reduce DI enrollment. In particular, employers became responsible for wage payment of sick listed workers in 1996, and DI benefit costs are experience rated for permanent workers since 1998. While there is evidence that these incentives have gradually contributed to more preventative and reintegration activities of employers, the introduction of the so-called "Gatekeeper Protocol" (in April 2002) is generally considered as the most effective policy change that has taken place. The Gatekeeper protocol specifies all the legal responsibilities of employers and their sick listed workers. As such, the Social Security Administration is no longer involved in the process of checking and reintegrating sick workers, but merely acts as a gatekeeper of the DI program. The Gatekeeper protocol forces employers to focus their attention at the onset of a sickness period. In contrast with the gradual impact of increased employer incentives in the Nineties, it seems that the protocol has had an almost immediate and persistent impact on the DI inflow rate (De Jong, Lindeboom, Van der Klaauw, 2011; Koning \& Lindeboom, 2015). In addition, both employer and worker incentives and obligations enhanced as a result of the extension of the sickness benefit period from one to two years in 2004 .

To understand why the Gatekeeper protocol has been successful in curbing DI inflow, it is important to realize that it prescribes a series of actions that should be taken in order to be eligible for DI benefits. After six weeks of absence, the employer and employee should make a 
first assessment on the medical cause and the functional limitations. On the basis of this assessment, they draft an accommodation and rehabilitation pan (or "reintegration plan") that specifies the steps that should be taken to resume work at the current or new job and the accommodated circumstances that are needed for this. At the same time, a case manager of the Social Security Administration is appointed and dates are determined at which the plan will be evaluated. The plan should be finalized in the eighth week of absence. If the worker has not returned to work after about three months prior to the end of the sickness waiting period, he files a DI benefit claim. The case manager decides whether the reintegration efforts of the employer and employee have been sufficient. If this condition is met, a doctor from the Social Security Administration determines the degree of disability of this worker at the end of the waiting period. In case of negligence the employer is held responsible and has to continue providing sick pay for a maximum of twelve months.

In light of the dramatic decrease of new DI awards since 2002 (see also figure 1), Koning and Lindeboom (2015) argue that the protocol has accelerated the cost- and risk awareness of employers, as well as the specific ways that are needed for disability prevention. Short-term absenteeism could no longer be left unnoticed by managers, with the protocol providing guidance to employers in their new role in the reintegration process. As it seems, employers have become more aware of the costs of two years of continued wage payments, as well as the DI benefit costs that were passed through in their DI premiums. Not surprisingly, however, criticism against the employer incentives and obligations has grown as well. Similar to experiences with the ADA in the U.S. that mandates employers to provide reasonable accommodations to employees with disabilities, the additional responsibilities may have induced employers to hire new workers with sufficiently good health conditions, thus reducing the costs associated with sickness or disability.

Persons who are not awarded disability insurance benefits may instead apply for unemployment insurance (UI) benefits if they are unemployed. During the period $2000-2010$ the UI replacement rate was 70 percent. The maximum entitlement period was dependent on a person's employment history, and ranged from a minimum of six months to a maximum five years. If a person is not eligible for either disability or unemployment insurance, he may apply for social assistance. This pays substantially lower benefits which are unrelated to previous earnings, and is means tested. Importantly, with the exception of a reduction in the maximum 
duration from 60 to 38 months in October 2006, there have been no major reforms in the UI program during the period of analysis.

Health insurance coverage was universal in the Netherlands during the period of analysis. Moreover, and more importantly, the Dutch health insurance system, by contrast to the DI system, has never been perceived as a source of labor market distortions.

\section{Descriptive Analysis}

We use the Dutch Labor Force Survey (LFS) for 2000 - 2010 to provide first, descriptive, evidence of the effect of the DI reforms on the labor market opportunities of people with health problems or a disability. The LFS is a rotating panel, administered by Statistics Netherlands, in which respondents are interviewed during five consecutive quarters. Many labor market statistics published by Statistics Netherlands, including for example the unemployment rate statistic, are based on the LFS.

Our analyses are limited to those aged 25 - 58 since this group has strong labor force attachment. Sick and disabled workers are identified by two questions. First, respondents are asked: "Do you suffer from one or more chronic diseases, disorders or handicaps?" If a respondent gives an affirmative answer to this first question, he gets a second question of which the formulation depends on the employment status of the respondent. If the respondent is employed he is asked "Are you limited in carrying out your work?" and if unemployed he is asked "Are you limited by your health in getting work?"

This format of inferring work disability differs from other surveys such as the Current Population Survey and the Panel Study of Income Dynamics. This should not be surprising because there is "no agreed upon standard for asking about work disability" according to Banks, Kapteyn, Smith, and Van Soest (2008). More importantly however, the results of several experiments conducted by the authors to examine the effect of differences in question wording on reporting of disability prevalence suggest that there is no clear basis for preferring one form of question(s) over another.

The work disability questions have only been included in the survey as of 2000 , which is the reason why we do not use information from earlier years. The work disability questions are asked only during the first interview in the period 2000 - 2009, and either during the first or third interview in 2010. Hence, we have one health measure per respondent. We group respondents 
into three groups based on the above questions. Respondents who do not report to suffer from an (chronic) illness are said to be "healthy", respondents who have an (chronic) illness but who do not experience problems in carrying out or finding work are said to be "sick," and finally, respondents whose work is affected by their medical condition are said to be "disabled." In our analyses based on the LFS, we only use employment status at the interview during which the health questions were asked. Furthermore, the formulation of the disability questions in 2007 and 2008 differed considerably compared to the other years, which is why data for 2007 and 2008 have been excluded from the analyses.

Descriptive statistics organized by age group, sex, and disability status are reported for selected years in table 1 . The table shows that there are marked differences between healthy, sick, and disabled persons even in the rather narrow age and sex subsamples. The older or lower educated a person is, the more likely it is that he has a (severe) health problem. Disabled persons are much less likely to be employed relative to sick persons, who in turn are less likely to be employed than healthy persons.

Figure 2 documents the evolution of chronic illness and work-related disability rates over our sample period. Illness rates are slightly declining for men and women aged $25-39$, and roughly constant for older men and women. Disability rates have been gradually decreasing for men throughout the sample period. For women aged 40 - 58 there was a small increase in selfreported disability rates between 2000 and 2002, which was reversed afterwards. The decrease in self-reported disability during our sample period may be the result of improved population health. Alternatively (or additionally) the DI reforms may have affected the likelihood that individuals describe themselves as disabled, either through changed social norms about what constitutes as a disability or because more disabled people are working and for that reason do not report to be disabled any longer.

\section{Effects on employment}

To provide graphical evidence on how the series of DI reforms have affected employment, figure 3 plots the average employment rate by age group for healthy, sick, and disabled men and women. For nondisabled men aged 25 - 39 and 40 - 58 the development of the employment rate is remarkably similar and stable over time. For disabled men age 25 - 39 the employment rate was rather stable during the period 2001 - 2004, but has been decreasing afterwards. By contrast, 
the employment rate for men age 40 - 58 has been rather similar over the entire sample period. For nondisabled women in both age groups, the employment rate is steadily increasing, with the employment rate for the younger age group initially at a higher level. The employment rate for disabled women aged 25 - 39 slightly decreased during the period 2001 - 2006, and has moderately increased afterwards. For disabled women aged 40 - 58 the employment rate has been steadily increasing, but at a slower rate than employment for nondisabled women. The employment rate has developed remarkably similar for healthy and sick workers in all four demographic subgroups we analyze. Figure 3 therefore suggests that the employment opportunities of disabled men and women aged 25 - 39 have worsened relative to nondisabled men and women.

Table 2 reports ordinary least squares estimates of a dummy variable for employment on dummies for individual health status, year, age groups, three schooling groups, two race groups, and a full set of year $\times$ health status interactions. These year $\times$ health status interactions are the coefficients of main interest, because they describe the change in relative employment of the sick and the disabled. We do consider 2000 - 2001 as the pretreatment period, which is much shorter than in comparable analyses by DeLeire (2000) and Acemoglu and Angrist (2001). The years 2002 - 2006 are a "transition" period during which several DI reforms are implemented. We think of $2006-2010$ as the posttreatment years. The results in table 2 suggest an improvement in the employment opportunities of sick individuals across all four demographic groups. For disabled men aged 25 - 39 the relative employment rates initially increased, but this was reversed in 2005, the year in which the law that makes employers responsible for the first two years of sickness pay became effective. The relative employment rate of disabled men aged $40-$ 58 seems unaffected by the reforms. For women in both age groups the relative employment rate has decreased substantially over the sample period. The decrease is small and statistically insignificant in 2001, but increases substantively in 2002, the year in which the Gatekeeper protocol became effective. Over the remainder of the sample period the relative employment rate of disabled women has further declined.

As the relative employment rate of the disabled decreased for 3 of the 4 age/sex groups, this descriptive analysis provides suggestive evidence that the reforms of the disability program impose a significant cost on employers. This finding is in line with results from DeLeire (2000) and Acemoglu and Angrist (2001) that the ADA imposes a significant cost on employers. 
An important caveat to the above analysis is that it relies on a subjective health measure. To circumvent the well-known problems associated with subjective health measures, we next use rich administrative data that are described in the following section.

\section{Administrative Data and Empirical Implementation}

\subsection{Data and Sample Selection}

We next use rich administrative data from hospital admission records, social security records, and the municipality registers, which can be linked through an unique identifier for each individual. Taken together, they provide a population-level panel data set with information for every person about their demographic characteristics hospital admissions, and labor market outcomes.

The hospital register data contains information on both inpatient and daycare patients of almost all hospitals in the Netherlands from 1999 to 2005. For each hospital admission we observe (i) the admission and discharge data, (ii) whether or not it was an acute admission, and (iii) the main diagnosis. We follow García-Gómez et al. (2013) and identify a sudden decline in health (or "health shock") as an unscheduled hospitalization that requires immediate treatment and involves a stay of at least three nights. The admissions are required to involve a stay of at least three nights because unscheduled and acute hospitalizations may include less severe health problems such as a mild head injury. Also, we exclude hospitalizations due to pregnancy and child birth. Due to the unscheduled and acute nature of the hospital admissions it is plausible that they are exogenous to labor market outcomes.

We define workers who experienced an unscheduled and acute hospitalization of at least three nights, excluding those related to pregnancy and child birth, as the "treatment group." Workers who did not experience a hospitalization at all form the "control group." This means that workers with types of hospitalizations other than those in the treatment group are excluded from the analysis.

Treatment and control cases are further restricted to persons who in the year prior to the potential health shock were: (i) aged 25 - 58, (ii) working - excluding those who are on disability benefits in the year of the shock, since they must have been on sickness benefits in the year before the shock, and (iii) not admitted to a hospital. These sample selection criteria are similar to the ones imposed by García-Gómez et al. (2013). Furthermore, following Borghans, 
Gielen, and Luttmer (2014), we exclude all individuals who appear on more than one disability scheme at the same time (within a year; about three percent of the sample), because it is not clear whether they result from administrative or coding errors, or whether these persons are truly entitled to multiple different DI schemes.

\subsection{Empirical Implementation and Summary Statistics}

To investigate the effects of the DI reforms on the employment opportunities of people with health problems or disability we compare the effect of a health shock in a year before the reforms to the effect of a health shock in a year after the reform. Specifically, we focus on 2000 and 2005 as the two years in which a health shock can potentially occur. Given the sample selection criteria described before and data availability, 2000 is the earliest and 2005 the latest possible year. Moreover, and more importantly, people who get disabled in 2000 are not affected by introduction of the Gatekeeper protocol (in 2002) and prolongation of financing sick pay for employers (in 2004), whereas those who get disabled in 2005 are. Recall that especially the introduction of the Gatekeeper protocol is considered to be the most effective DI reform in the Netherlands, and that its incentives enhanced as a result of the extension of the sickness benefit period from one to two years in 2004.

The sample selection described in the previous section results in a sample of 31,386 unscheduled and acute hospitalizations with a stay of at least three nights in 2000, and 27,911 hospital admissions in 2005.

Table 3 shows the relative frequency of the unscheduled admission in 2000 by diagnoses on the basis of the International Classification of Diseases 9 (ICD-9) for the same four main demographic groups as before. Descriptive statistics for 2005 look very similar and are therefore omitted. Not surprisingly, there are many more unscheduled hospitalizations among men and women aged $40-58$ than among their counterparts aged $25-39$. Moreover, there are notable differences in the relative importance of certain diseases. For example, for men aged $40-58$, diseases of the circulatory system account for 36 percent of the hospital admissions, whereas for younger men this is only 10 percent. Moreover, circulatory diseases account for 9 percent of the hospital admissions among women aged $25-39$, whereas it accounts for 21 percent of the hospital admission among women aged 40 - 58. By contrast, injuries are the most important cause of a hospital admission among men aged 25 - 39, accounting for 29 percent of the 
admissions. Among all other groups, injuries account for only 14 percent of the admissions. These two examples illustrate that there are marked differences in the causes of hospital admission between men and women, and between age groups.

In the empirical analyses, we compare the labor market outcomes of persons who have had an unscheduled and urgent hospitalization with those who have not, for up to four years after the year of the potential health shock, and for two years in which the health shock can take place. We investigate how labor market outcomes evolve for up to 4 years. That is, since we focus on 2000 and 2005 as the years in which the health shock potentially can occur, we study outcomes in the periods 2001 - 2004 and 2006 - 2009. We are particularly interested in the difference in the "health shock - no health shock" outcomes between 2005 and 2000, and interpret this difference in the light of the major DI reforms that have taken place. To examine the effect of the DI reforms we estimate the following model

$$
Y_{i t}=\alpha_{t}+\beta_{t} S_{i}+\gamma_{t} T_{i}+\delta_{t}\left(S_{i} \cdot T_{i}\right)+\theta_{s t}^{\prime} X_{i}+\epsilon_{i t}, \quad t=1,2,3,4,
$$

where $i$ refers to the person; $t$ to the number of years passed since the year of the shock; $S_{i}$ indicates whether or not person $i$ had a health shock; $T_{i}$ equals 1 if the year of the health shock is 2005, and zero otherwise. $X$ is a vector of covariates, including dummies for five year age groups, nationality (Native, Nonnative non-Western, Nonnative Western), household size, municipality size, province, and labor income from the year prior to the possible health shock (in quartiles). The effects of these covariates are allowed to differ both by the time passed since the possible health shock, and by whether or not a person actually had a health shock (as indicated by the subscripts $s$ and $t$ on $\theta$ ). Furthermore, the subscript $t$ on the other parameters indicates that we allow the effects to differ by the time passed since the health shock. Instead of estimating the model for each $t$, we pool all observations and cluster standard errors on the individual level. The parameters $\left(\beta_{1}, \beta_{2}, \beta_{3}, \beta_{4}\right)$ give the effect of a health shock in 2000 . The parameters of main interest are $\left(\delta_{1}, \delta_{2}, \delta_{3}, \delta_{4}\right)$ which give the difference in "health shock - no health shock" outcomes between 2005 and 2000. If the reforms have been effective in reducing the extent to which ill health reduces employment opportunities and a person's earnings capacity, then we expect these parameters to have a positive sign for employment and labor income. 
The consequences of a health shock are likely to differ by age. Older people are more likely to experience a more serious deterioration of health, and have fewer incentives to invest in work resumption due to lower remaining working-life expectancy. Older people are thus less likely to return to work after a health shock (Charles, 2003). Effects are likely to differ by gender as well. It is therefore important to look for heterogeneity in the effects of the DI reforms by age and gender. Hence, we estimate the model separately for men aged 25 - 39, men aged $40-58$, and for women in these two age groups. Our analyses are limited to those aged $25-58$ since this group has strong labor force attachment.

In table 4 we show descriptive statistics for several variables by age and sex, and for both years of hospitalization. "Treatment" refers to persons who have experiences an unscheduled and acute hospitalization, whereas "control" refers to people who did not experience a hospitalization at all in the relevant year. Older people are more likely to experience a health shock and poorer people as well. This is consistent with the well-known socioeconomic gradient in health.

\subsection{Results}

To begin, we present results for the probability to receive DI benefits in table 5. For young men the probability to receive DI benefits is 3.5 percentage points higher in the year after a health shock, it increases to 4.6 percentage points in the next year, and then declines to 4 percentage points in the following two years. For older men, a sudden deterioration of health initially increases the probability of DI receipt by 6.2 percentage points, which increases to 7.8 percentage points in the second year, and increases further to around 8.5 percentage points in the third and fourth year. For women in both age groups, the probability to receive DI benefits is initially smaller compared to their male counterparts. However, in the third or fourth year after the health shock, the probability to receive DI benefits is higher among women. Both among men and women, the probability of DI receipt is larger for those aged 40 - 58 than for their younger counterparts. There exist several potential reasons for this observation. First, younger people may have stronger incentives to return to the labor force because they have fewer options to replace lost income. Second, younger people benefit for a longer time period from re-entry. Finally, younger people face a different and perhaps less severe health shock (see also table 3 ). We explore the last explanation in more detail below. 
The next set of estimates in table 5 show the difference of the effect of a health shock between 2005 and 2000 (the $\delta$ coefficients of model (1)). The fact that the estimates for the first year after the shock are larger than for the remaining period is to be expected because since 2004 an ill person needs to wait two years before becoming eligible to receive DI benefits. Two years after a health shock, a man aged 25 - 39 is 3.4 percentage points less likely to receive DI benefits and this effect declines slightly in the next two years. For older men, the reduction in the probability to receive DI benefits is larger than for younger men and it also increases over time. Among women the effects are larger for those aged 40 - 58. A potential explanation for the observation that the effects are larger for those aged $40-58$ is that the disability reforms have been effective in reducing the use of the disability program as a substitute pathway into unemployment and early retirement. The results further indicate that for everyone it has become considerably more difficult to receive DI benefits. This should not be surprising given the substantive decline in the DI award rate, as shown in figure 1, that followed the introduction of strict sickness monitoring obligations for employers.

Since it has become more difficult to enter DI after a sudden decline in health, individuals may substitute between social assistance programs instead of resuming work. For example, Borghans et al. (2014) found that for each euro of lost DI benefits individuals collect 30 cents more from other social assistance programs. Substitution between social assistance programs reduces the welfare impact of the disability reforms. The first set of results in table 6 show that a sudden decline in health increases the probability of unemployment benefit receipt by about 1.5 -2 percentage points for men and women aged $25-39$. The second set of results indicates that after the disability reforms the probability to receive unemployment insurance benefits is smaller than before. This suggests that the disability reforms have not led to substitution between the disability and unemployment programs. Table 7 shows similar results for the probability to receive welfare benefits: a health shock does not affect the probability of welfare receipt and this has not changed after the disability reforms.

The results so far indicate that after the DI reforms it has become more difficult to enter the disability program. Furthermore, individuals did not substitute to the unemployment or welfare program. However, a remaining concern may be that the reforms have led to an increase of false rejections (in an attempt to reduce false admissions) and have not led to improved employment opportunities for disabled workers. To investigate this, we examine how the 
probability to be employed after a health shock has changed after the DI reforms. In table 8 we show the employment effects of an unscheduled and urgent hospital admission in 2000 (i.e., the $\beta$ coefficients of model (1)), as well as the effect of an unscheduled and urgent hospitalization in 2005 compared to 2000 (i.e., the $\delta$ coefficients of model (1)). The effect of a health shock in 2000 is already substantial in the year following the health shock in all four demographic groups; it reduces employment by almost 4 percentage points for men in both age groups, by 3.6 percentage point for women aged $25-39$ and by 3 percentage points for women aged $40-58$. In the remaining years after the unscheduled hospital admission the probability to work reduces further for all four age/sex groups. Younger men (women) are significantly less likely than older men (women) to suffer from a circulatory disease or to get cancer, illnesses that may lead to a longer (or permanent) withdrawal from the labor force. Thus, the nature of the health shock may explain why the employment effects are smaller for younger men and women. An alternative explanation is that younger people have fewer options to replace income. Yet another explanation is that younger people have more to gain from re-entering the labor force.

The next set of estimates in table 8 show how the effect of a health shock on employment differs in 2005 compared to 2000 . For all four groups, the relative employment probability has improved by $2-4$ percentage points. In part this can be explained by the fact that after 2004 the employer is responsible for the first two years of sick pay, and by the fact that in our data workers who receive sickness benefits are classified as employed. A consequence of the DI reforms may have been that after the onset of a severe health problem workers initially remain employed, but eventually become unemployed due to further deterioration of their health (possibly as a result of continued employment). In light of this, it is important to note that our results show that the improvement in the relative employment probability persists, also after two years. This suggests that the DI reforms have not been at the costs of the well-being of workers with health problems, and thus have been successful in targeting the program to those having substantial health problems.

The effects of an unscheduled and acute hospital admission on earnings are shown in table 9. Similar to García-Gómez et al. (2013) we find that income from labor is reduced, although not for men aged 40 - 58. Men aged 25 - 39 experience a substantial loss of labor income; initially around 3500 euros, and further declining to a loss of 4400 euros in the fourth year. Similar effects, although smaller in magnitude are found for women aged $25-39$ and $40-58$. By 
contrast, for men aged $40-58$ there is no clear indication that their labor income is reduced after a hospitalization. While we found that employment opportunities and the probability to remain in the same job improved after the DI reforms, there is no clear evidence that this also happened for labor income, with the exception of women aged 40 - 58. For them there seems to have been a positive, and economically meaningful, effect (compared to the reduction in earnings after a health shock).

The results so far can be summarized as follows. A worker who experiences an unscheduled and acute hospital admission after the DI reforms is less likely to enter disability insurance, is more likely to stay employed, but still experiences a decrease in labor income. A possible explanation for these results is that the DI reforms have been effective in reducing the extent to which ill health reduces employment opportunities. However, there is scope for improvement regarding a person's earnings capacity.

\section{Do effects differ by type of health shock?}

Next, we further examine the role of the nature of the health shock. In his analysis of the effects of changes in health status on health insurance coverage and labor market outcomes, McClellan (1998) makes an interesting distinction between (i) major health events, (ii) chronic illnesses, and (iii) accidents. Major health events - such as cancer, heart attack, or stroke - have a substantial immediate effect and imply long-term functional limitations. Chronic illnesses - such as diabetes, lung disease, arthritis, or heart failure - generally only moderately limit current functioning, but may result in more severe impairments due to progression of the disease. Finally, accidents have substantial immediate effects on functioning, but are less likely to result in severe long-term impairments.

Among the young men and women who experience a health shock, around 5 percent has a major health shock, 25 percent is due to a chronic illness, and the remaining 70 percent are due to accidents. Among men aged $40-58$ who are hospitalized, 20 is due to a major health event, 30 percent due to a chronic illness, and 50 percent due to an accident. Among women aged $40-$ 58 the distribution is significantly different, with only 10 percent of the hospitalizations due to a major health event, 30 percent due to a chronic illness, and 60 percent due to accidents. Major health events are thus considerably more important among men aged 25 - 39 compared to 
women in that age category. Major health events are also much more important among older men and women relative to their younger counterparts. The distribution is very similar for both years.

A major heath event has a much more negative impact on the probability to remain employed for young men and women, compared to the other two categories. For example, for men aged 25 - 39, a major health shock lowers the probability to be employed initially by 9 percentage points and by 20 percentage points in the fourth year. The onset of a chronic illness results in a 3 to 6 percentage points lower employment probability in the four-year follow-up period, but these effects are not all precisely measured. For older men, a major health event lowers the employment probability by a similar magnitude as that for younger men. By contrast to younger men, for men aged $40-58$, the onset of a chronic illness and an accident are also important reason for labor market withdrawal. The onset of a chronic illness results in a $6-13$ percentage points decrease in the probability to be employed. An accident lowers it by 5 percentage points in the fourth year. For older men these effects are also statistically significant.

Table 10 only reports the $\delta$ coefficients from model (1), where $S_{i}$ now is a vector of binary variables indicating whether a person had a major health event, experienced the onset of a chronic illness, or had an accident. For young men and women, the largest improvement in absolute sense is made among those workers who experience a major health event, although the improvement is imprecisely measured among women. That the largest improvement takes place among those experiencing a major health event is not surprising, because it has by far the biggest effect on the employment probability. For men aged $40-58$, there is little improvement in the employment probability after a major health event.

After the DI reforms, the onset of a chronic illness does no longer result in labor market withdrawal as often as often as before. The improvement mostly offsets the relatively small negative effect of a chronic illness that existed prior to the reforms. For older men, the onset of a chronic illness remains having a negative effect on the employment probability, but it is substantially less frequently a reason for labor market withdrawal after the DI reforms. In fact, the results suggest that most of the improvement in employment opportunities among people who have experienced an unscheduled and acute hospitalization is achieved among those who experience the onset of a chronic illness. This seems intuitively plausible because a major health event leads to an immediate and substantial reduction in functional limitations, whereas the onset of a chronic illness only leads to a moderate decline. This in turn suggests that the DI reforms 
have improved the "targeting efficiency" of the program: more than before the reforms DI receipt is restricted to those who have substantial health problems.

\section{Sensitivity Analysis}

A key assumption underlying our analysis is that the business cycle does not affect the labor market recovery of individuals who experience a health shock. To test whether the business cycle affects our result, we estimate a model that includes the unemployment rate at the province level (province dummies are no longer included). Specifically, we estimate the following model:

(2) $Y_{i t}=\alpha_{t}+\beta_{t} S_{i}+\gamma_{t} T_{i}+\delta_{t}\left(S_{i} \cdot T_{i}\right)+\theta_{s t}^{\prime} X_{i}+\rho_{t} U_{i}+\varphi_{t}\left(S_{i} \cdot U_{i}\right)+\epsilon_{i t}, \quad t=1,2,3,4$,

where $U_{i}$ is the unemployment rate in the province in which individual $i$ is living in the year of the health shock. If the business cycle does not affect the labor market recovery of individuals who experience a health shock, then we expect the $\delta$ coefficients, our parameters of main interest, to be similar in specifications model (1) and model (2). Table 11 reports the estimated $\delta$ coefficients for the probability to receive DI benefits and for the probability to be employed. It is reassuring that the effects on the probability to receive DI benefits remain similar across specifications (cf. table 5). For the probability to be employed the estimates differ between both specifications, in particular for men and women aged 25 - 39. For men aged $25-39$, the coefficients become small and insignificant. For women aged 25 - 39, the coefficients remain substantial but also become insignificant. For men and women aged 40 - 58, the coefficients remain more similar and significant. This suggests that the disability reforms have been mainly beneficial for older workers.

Selective mortality could bias our results since individuals experiencing an acute hospitalization are more likely to die within the observation period than individuals who are not hospitalized. To examine whether this is a problem, we have repeated the analysis using only individuals who remain alive throughout the whole four year follow-up period. The estimates obtained from this restricted sample are very similar to those generated by the full sample (results are available upon request).

Our estimates of the effects of a health shock on labor market outcomes may be biased due to the omission of individual characteristics - such as health, job characteristics, and education - 
that are potentially correlated with both the propensity to be hospitalized and labor market outcomes. To identify the effects of a health shock we closely follow García-Gómez et al. (2013). These authors have also investigated whether their analysis has been compromised by the omission of individual characteristics. Using a Dutch household survey which provides detailed information on health, health behaviors, and socio-economic characteristics, García-Gómez et al. (2013) conclude that there is no reason to be concerned that the exclusion of certain characteristics compromises their estimation strategy. Moreover, even if the omission of certain characteristics does bias the estimates of the effect of a health shock, our parameters of main interest, the difference between the effects of a health shock in 2000 and 2005, would not be compromised as long as the bias remains constant over time.

\section{Discussion}

In this paper we examine whether the DI reforms in the Netherlands have had the unintended consequence of lowering employment and deterring the hiring of workers with health problems or disabilities. An important component of the reforms was to make employers responsible for paying sickness benefits, and to strengthen their sickness monitoring obligations. While these employer incentives stimulate preventive and reintegration activities, employers are also confronted with substantial costs when an employee gets sick which may make them reluctant to hire workers whose medical history put them at risk for becoming disabled. If the latter effect dominates, the Dutch DI reforms may have had the unintended consequence of lowering employment opportunities of workers with health problems or disability.

The descriptive analysis based on the Dutch Labor Force Survey suggests that the employment opportunities of disabled men and women have worsened relative to nondisabled men and women. This analysis, however, relies on a subjective health measure, which may itself be endogenous if people are less (or more) inclined to report a health problem or disability in response to the reforms. To circumvent this problem, we use rich administrative data that allow us to utilize exogenous variation in health. The analysis based on these rich administrative data clearly show that the labor market position of workers who experience an exogenous shock to their health has improved: they are less likely to receive disability insurance benefits and they are more likely to remain employed. 
On the basis of our analysis, we conclude that the DI reforms implemented by the Dutch government have substantially improved work resumption among employees, but may have inadvertently reduced the hiring opportunities of people with health problems or a disability. The latter part of the conclusion is further strengthened by other descriptive evidence presented in Koning and Lindeboom (2015). In the Netherlands, the most straightforward way for Dutch firms to circumvent experience-rating incentives is to hire workers on temporary contracts. In case a worker on a temporary contract becomes ill, costs are not assigned to individual employers but to a collective fund. Koning and Lindeboom (2015) do not offer causal evidence on the effect of enhanced employer incentives, but do show that the share of DI benefits awarded to workers with a temporary contract increased from 42 percent in 2007 to 55 percent in 2011 . They argue that this increase cannot be fully explained by the (much smaller) increase in the share of workers with temporary contracts. This also suggests that "vulnerable groups with bad health conditions have sorted into flexible jobs."

The rapid growth of the DI program faced in many countries poses significant financial risks to those programs (e.g., the projected depletion of the U.S. SSDI Trust Fund in 2016) as well as the entire Social Security program more broadly. Proposals on how to reform the U.S. disability program, such as Autor and Duggan (2010) and Burkhauser and Daly (2011), suggest to increase the incentives faced by firms (among other changes). Our paper shows that enhancing employer incentives might indeed be a fruitful way to a more sustainable growth path of DI programs. 


\section{References}

Acemoglu, D., \& Angrist, J. D. (2001). Consequences of Employment Protection? The Case of The Americans with Disabilities Act. Journal of Political Economy, 109, 915-957.

Autor, D. H. (2011). The Unsustainable Rise of the Disability Rolls in the United States: Causes, Consequences, and Policy Options (Working Paper). Boston, MA: MIT.

Autor, D. H., \& Duggan, M. G. (2006). The Growth in the Social Security Disability Rolls: A Fiscal Crisis Unfolding. Journal of Economic Perspectives, 20, 71-96.

Autor, D. H., \& Duggan, M. G. (2010). Supported Work: A Proposal for Modernizing the U.S. Disability Insurance System (Report). Washington, D.C.: The Center for American Progress and The Hamilton Project.

Banks, J., Kapteyn, A., Smith, J. P., \& Van Soest, A. (2008). Work Disability is a Pain in the ****, Especially in England, The Netherlands, and the United States. In D. Cutler \& D. A. Wise (Eds.), Health in Older Ages: The Causes and Consequences of Declining Disability Among the Elderly (pp. 251-294). Chicago, IL: The University of Chicago Press.

Beegle, K., \& Stock, W. A. (2003). The Labor Market Effects of Disability Discrimination Laws. Journal of Human Resources, 38, 806-859.

Bell, D., \& Heitmueller, A. (2009). The Disability Discrimination Act in the U.K.: Helping or Hindering Employment Among the Disabled? Journal of Health Economics, 28, 465-480.

Borghans, L., Gielen, A. C., \& Luttmer, E. F. (2014). Social Support Substitution and the Earnings Rebound: Evidence from a Regression Discontinuity in Disability Insurance Reform. American Economic Journal: Economic Policy, 6, 34-70.

Bound, J. (1991). Self-Reported versus Objective Measures of Health in Retirement Models. Journal of Human Resources, 26, 106-138.

Burkhauser, R. V., \& Daly, M. C. (2011). The Declining Work and Welfare of People with Disabilities: What Went Wrong and a Strategy for Change (Report). Washington, D.C.: American Enterprise Institute.

Burkhauser, R. V., Daly, M. C., \& De Jong, P. (2008). Curing the Dutch Disease: Lessons of the United States Disability Policy (Working Paper No. 2008-188). Ann Arbor: MI: Michigan Retirement Research Center.

Charles, K. K. (2003). The Longitudinal Structure of Earnings Losses Among Work-Limited Disabled Workers. Journal of Human Resources, 38, 618-646.

De Jong, P., Lindeboom, M., \& Van der Klaauw, B. (2011). Screening Disability Insurance Applications. Journal of the European Economic Association, 9, 106-129. 
DeLeire, T. (2000). The Wage and Employment Effects of the Americans with Disabilities Act. Journal of Human Resources, 35, 693-715.

García-Gómez, P., Van Kippersluis, H., O’Donnell, O., \& Van Doorslaer, E. (2013). Long-Term and Spillover Effects of Health Shocks on Employment and Income. Journal of Human Resources, 48, 873-909.

Koning, P., \& Lindeboom, M. (2015). The Rise and Fall of Disability Insurance Enrollment in the Netherlands. Journal of Economic Perspectives, 29, 151-172.

Kreider, B. (1999). Latent Work Disability and Reporting Bias. Journal of Human Resources, 34, 734-769.

Kruse, D., \& Schur, L. (2003). Employment of People with Disabilities Following the ADA. Industrial Relations, 42, 31-66.

Lalive, R., Zweimüller, J., \& Wuellrich, J.P. (2013). Do Financial Incentives Affect Firms' Demand For Disabled Workers? Journal of the European Economics Association, 11, 25-58.

McClellan, M. (1998). Health Events, Health Insurance, and Labor Supply: Evidence from the Health and Retirement Study. In D.A. Wise (Ed.), Frontiers in the Economics of Aging (pp. 301350). Chicago, IL: The University of Chicago Press.

OECD. (1992). Employment Policies for People with Disabilities. Paris, France: OECD Publishing.

OECD. (2003). Transforming Disability into Ability: Policies to Promote Work and Income Security for Disabled People. Paris, France: OECD Publishing.

OECD. (2010). Sickness, Disability and Work: Breaking the Barriers. Paris, France: OECD Publishing.

Parsons, D. (1991). Self-Screening in Targeted Public Transfer Programs. Journal of Political Economy, 99, 859-876. 


\section{Figures}

Figure 1: Disability Insurance Recipiency and Award Rates per Adult Ages 20-65

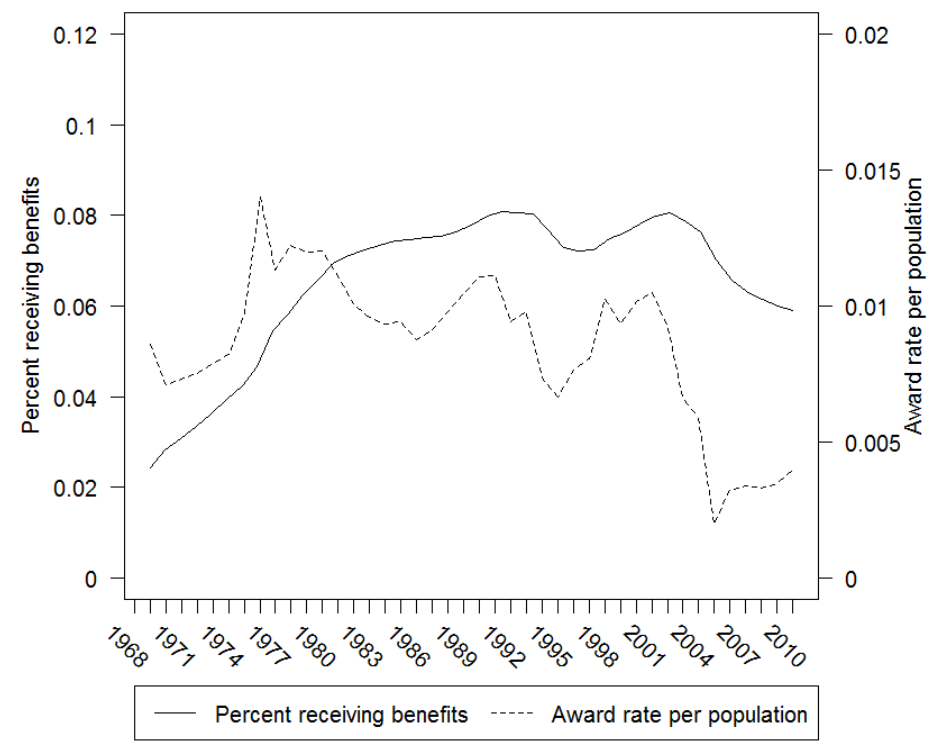

Source: Author's calculations from the data of Statistics Netherlands (publicly available through statline.cbs.nl)

Figure 2: Probability to have an (chronic) illness (left panel) or a work disability (right panel)
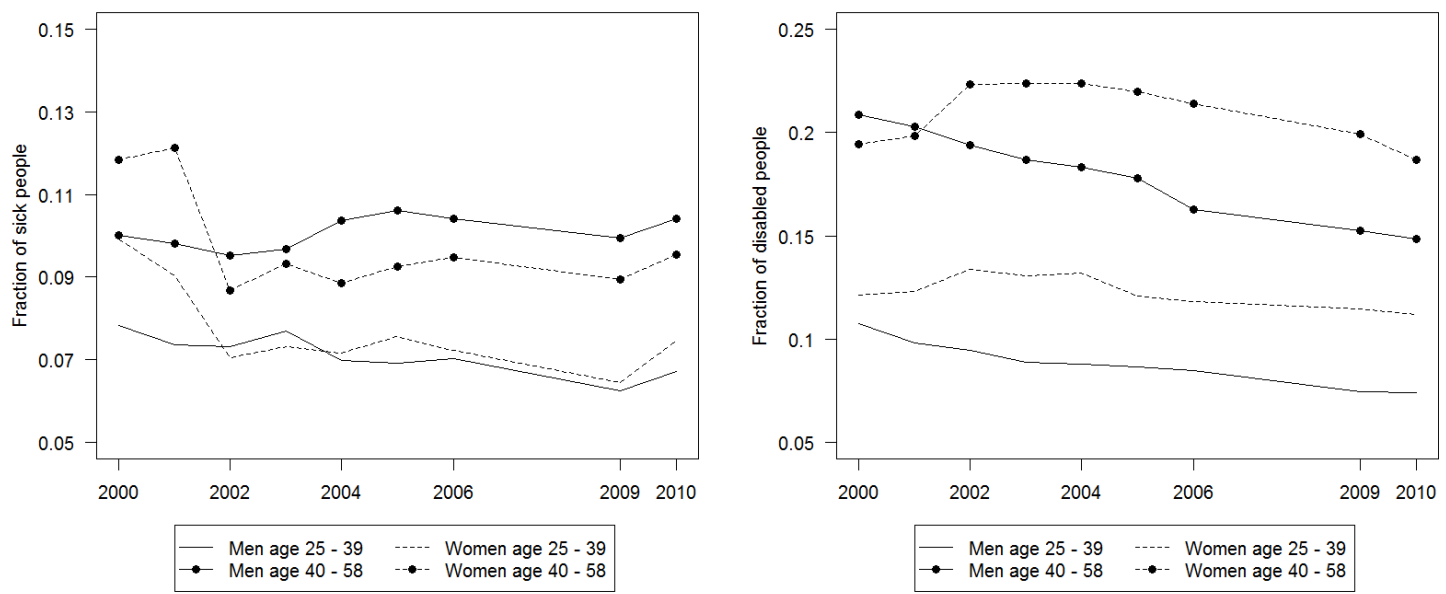
Figure 3: Employment probability for men age 25-39 (upper left panel), men age 40-58 (upper right panel), women age 25-39 (lower left panel), and women age 40-59 (lower right panel)
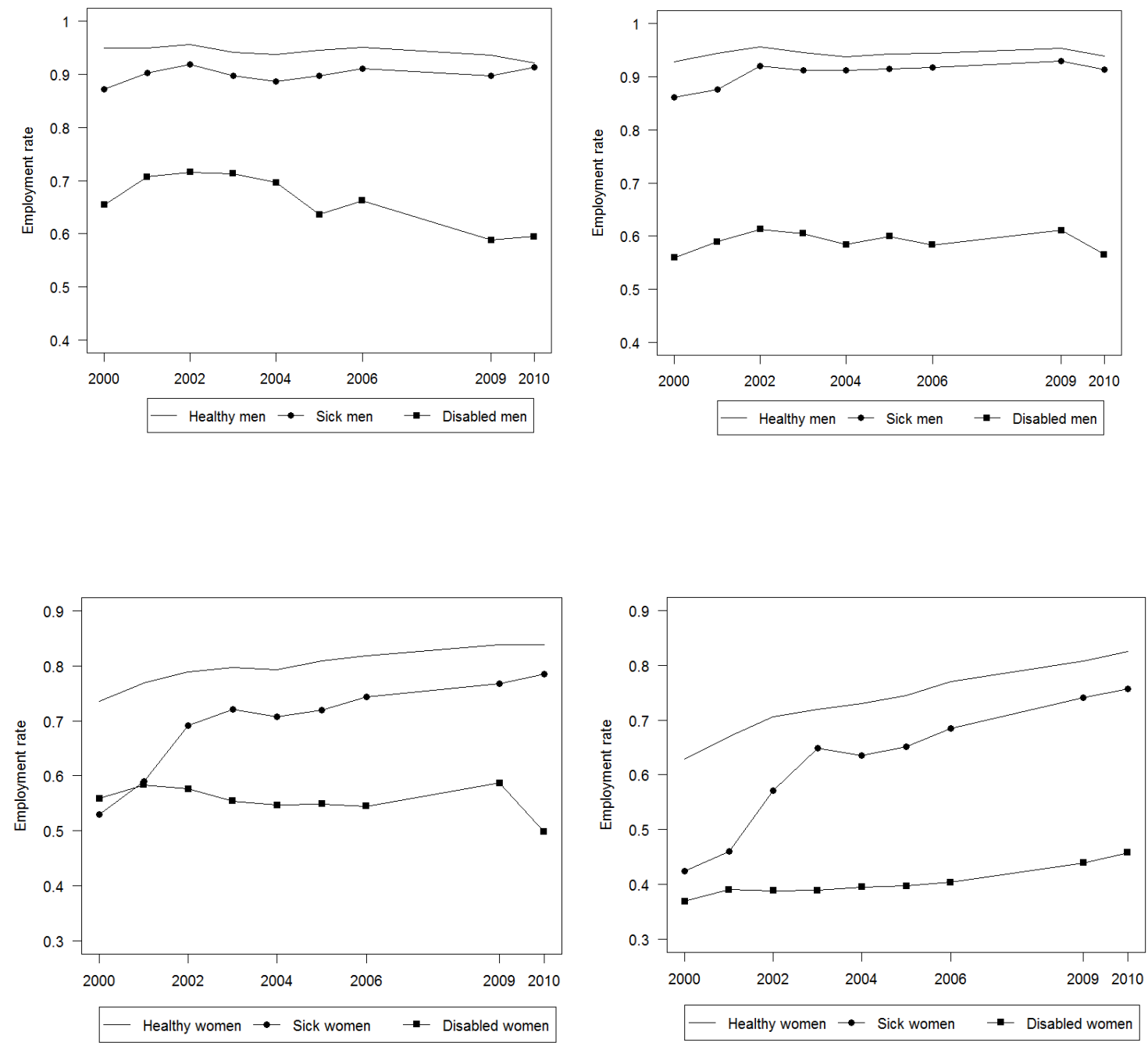
Tables

Table 1: Summary Statistics for the Dutch Labor Force Survey

\begin{tabular}{|c|c|c|c|c|c|c|c|c|c|}
\hline & \multicolumn{3}{|c|}{2000} & \multicolumn{3}{|c|}{2004} & \multicolumn{3}{|c|}{2009} \\
\hline & Healthy & Sick & Disabled & Healthy & Sick & Disabled & Healthy & Sick & Disabled \\
\hline & \multicolumn{9}{|c|}{ Men aged $25-39$} \\
\hline Age & 32.26 & 32.84 & 33.17 & 32.50 & 32.90 & 33.46 & 31.98 & 32.44 & 32.39 \\
\hline Dutch & 0.95 & 0.94 & 0.94 & 0.95 & 0.96 & 0.95 & 0.95 & 0.98 & 0.94 \\
\hline Edu low & 0.27 & 0.35 & 0.48 & 0.20 & 0.23 & 0.36 & 0.20 & 0.24 & 0.41 \\
\hline Edu mid & 0.44 & 0.44 & 0.38 & 0.45 & 0.48 & 0.45 & 0.42 & 0.47 & 0.45 \\
\hline Edu high & 0.28 & 0.20 & 0.13 & 0.34 & 0.28 & 0.17 & 0.38 & 0.28 & 0.14 \\
\hline Employed & 0.95 & 0.87 & 0.65 & 0.94 & 0.89 & 0.70 & 0.94 & 0.90 & 0.59 \\
\hline \multirow[t]{2}{*}{ Observations } & 6,657 & 641 & 879 & 10,035 & 832 & 1,050 & 5,066 & 367 & 437 \\
\hline & \multicolumn{9}{|c|}{ Men aged $40-58$} \\
\hline Age & 47.70 & 48.42 & 49.27 & 47.88 & 48.83 & 49.68 & 48.13 & 49.00 & 49.58 \\
\hline Dutch & 0.97 & 0.97 & 0.96 & 0.98 & 0.98 & 0.97 & 0.98 & 0.96 & 0.96 \\
\hline Edu low & 0.28 & 0.35 & 0.51 & 0.25 & 0.29 & 0.41 & 0.23 & 0.28 & 0.40 \\
\hline Edu mid & 0.41 & 0.43 & 0.34 & 0.39 & 0.41 & 0.39 & 0.40 & 0.39 & 0.41 \\
\hline Edu high & 0.30 & 0.23 & 0.14 & 0.35 & 0.29 & 0.19 & 0.37 & 0.32 & 0.18 \\
\hline Employed & 0.93 & 0.86 & 0.56 & 0.94 & 0.91 & 0.58 & 0.95 & 0.93 & 0.61 \\
\hline \multirow[t]{2}{*}{ Observations } & 6,440 & 933 & 1,945 & 10,772 & 1,565 & 2,767 & 6,590 & 875 & 1,342 \\
\hline & \multicolumn{9}{|c|}{ Women aged $25-39$} \\
\hline Age & 32.37 & 32.57 & 32.50 & 32.49 & 32.69 & 32.89 & 32.31 & 33.07 & 32.75 \\
\hline Dutch & 0.94 & 0.95 & 0.94 & 0.95 & 0.94 & 0.95 & 0.92 & 0.94 & 0.94 \\
\hline Edu low & 0.27 & 0.38 & 0.38 & 0.19 & 0.24 & 0.31 & 0.16 & 0.22 & 0.31 \\
\hline Edu mid & 0.48 & 0.47 & 0.47 & 0.47 & 0.46 & 0.47 & 0.43 & 0.48 & 0.44 \\
\hline Edu high & 0.25 & 0.15 & 0.15 & 0.34 & 0.29 & 0.21 & 0.41 & 0.29 & 0.24 \\
\hline Employed & 0.74 & 0.53 & 0.56 & 0.79 & 0.71 & 0.55 & 0.84 & 0.77 & 0.59 \\
\hline \multirow[t]{2}{*}{ Observations } & 7,066 & 900 & 1,100 & 10,726 & 966 & 1,778 & 5,436 & 427 & 760 \\
\hline & \multicolumn{9}{|c|}{ Women aged $40-58$} \\
\hline Age & 47.64 & 48.85 & 48.72 & 47.96 & 48.75 & 49.16 & 47.99 & 48.15 & 49.24 \\
\hline Dutch & 0.97 & 0.95 & 0.96 & 0.97 & 0.98 & 0.97 & 0.97 & 0.96 & 0.97 \\
\hline Edu low & 0.44 & 0.53 & 0.54 & 0.35 & 0.40 & 0.47 & 0.26 & 0.31 & 0.42 \\
\hline Edu mid & 0.37 & 0.32 & 0.32 & 0.38 & 0.38 & 0.34 & 0.45 & 0.43 & 0.41 \\
\hline Edu high & 0.19 & 0.14 & 0.14 & 0.26 & 0.21 & 0.17 & 0.29 & 0.27 & 0.18 \\
\hline Employed & 0.63 & 0.42 & 0.37 & 0.73 & 0.64 & 0.40 & 0.83 & 0.76 & 0.46 \\
\hline Observations & 6,835 & 1,177 & 1,932 & 11,309 & 1,456 & 3,680 & 4,790 & 637 & 1,246 \\
\hline
\end{tabular}


Table 2: Regression estimates for the probability to be employed

\begin{tabular}{|c|c|c|c|c|}
\hline & \multicolumn{2}{|c|}{ Men } & \multicolumn{2}{|c|}{ Women } \\
\hline & Age $25-39$ & Age $40-58$ & Age 25 - 39 & Age $40-58$ \\
\hline \multirow[t]{3}{*}{ Sick x 2001} & 0.025 & 0.040 & -0.006 & -0.015 \\
\hline & $(0.014)$ & $(0.019)$ & $(0.014)$ & $(0.018)$ \\
\hline & [1.768] & [2.155] & {$[-0.412]$} & {$[-0.852]$} \\
\hline \multirow[t]{3}{*}{ Sick x 2002} & 0.030 & 0.095 & 0.024 & 0.053 \\
\hline & $(0.014)$ & $(0.020)$ & $(0.014)$ & $(0.019)$ \\
\hline & [2.073] & [4.780] & [1.754] & [2.807] \\
\hline \multirow[t]{3}{*}{ Sick x 2003} & 0.024 & 0.121 & 0.025 & 0.108 \\
\hline & $(0.014)$ & $(0.020)$ & $(0.014)$ & $(0.018)$ \\
\hline & [1.688] & [6.156] & [1.851] & [5.847] \\
\hline \multirow[t]{3}{*}{ Sick x 2004} & 0.015 & 0.111 & 0.035 & 0.082 \\
\hline & $(0.014)$ & (0.019) & $(0.013)$ & $(0.018)$ \\
\hline & [1.075] & [5.758] & [2.702] & [4.502] \\
\hline \multirow[t]{3}{*}{ Sick x 2005} & 0.020 & 0.115 & 0.033 & 0.086 \\
\hline & $(0.015)$ & $(0.019)$ & $(0.013)$ & $(0.018)$ \\
\hline & [1.388] & {$[5.930]$} & [2.496] & [4.751] \\
\hline \multirow[t]{3}{*}{ Sick x 2006} & 0.028 & 0.122 & 0.033 & 0.095 \\
\hline & $(0.015)$ & $(0.020)$ & (0.013) & $(0.018)$ \\
\hline & [1.842] & [6.008] & [2.437] & [5.140] \\
\hline \multirow[t]{3}{*}{ Sick x 2009} & 0.024 & 0.126 & 0.035 & 0.101 \\
\hline & $(0.018)$ & $(0.024)$ & $(0.015)$ & $(0.020)$ \\
\hline & [1.349] & [5.177] & [2.351] & [4.938] \\
\hline \multirow[t]{3}{*}{ Sick x 2010} & 0.071 & 0.127 & 0.032 & 0.103 \\
\hline & $(0.020)$ & $(0.027)$ & $(0.017)$ & $(0.023)$ \\
\hline & [3.586] & [4.692] & [1.926] & [4.522] \\
\hline \multirow[t]{3}{*}{ Disabled x 2001} & 0.053 & -0.008 & 0.008 & -0.019 \\
\hline & $(0.013)$ & $(0.017)$ & $(0.010)$ & $(0.015)$ \\
\hline & [4.229] & {$[-0.458]$} & [0.745] & {$[-1.320]$} \\
\hline \multirow[t]{3}{*}{ Disabled x 2002} & 0.051 & -0.033 & 0.017 & -0.052 \\
\hline & $(0.013)$ & $(0.017)$ & $(0.010)$ & $(0.014)$ \\
\hline & {$[4.000]$} & {$[-2.000]$} & [1.659] & {$[-3.655]$} \\
\hline \multirow[t]{3}{*}{ Disabled x 2003} & 0.068 & -0.057 & 0.019 & -0.064 \\
\hline & $(0.013)$ & $(0.017)$ & $(0.010)$ & $(0.014)$ \\
\hline & [5.211] & {$[-3.428]$} & [1.789] & {$[-4.475]$} \\
\hline \multirow[t]{3}{*}{ Disabled x 2004} & 0.047 & -0.061 & 0.005 & -0.072 \\
\hline & $(0.013)$ & $(0.016)$ & $(0.010)$ & $(0.014)$ \\
\hline & [3.713] & {$[-3.753]$} & [0.511] & {$[-5.220]$} \\
\hline \multirow[t]{3}{*}{ Disabled x 2005} & -0.013 & -0.074 & 0.016 & -0.083 \\
\hline & $(0.013)$ & $(0.017)$ & $(0.010)$ & $(0.014)$ \\
\hline & {$[-1.002]$} & {$[-4.383]$} & {$[1.576]$} & {$[-5.885]$} \\
\hline \multirow[t]{3}{*}{ Disabled x 2006} & 0.006 & -0.083 & 0.001 & -0.094 \\
\hline & $(0.014)$ & $(0.017)$ & $(0.011)$ & $(0.014)$ \\
\hline & [0.476] & {$[-4.719]$} & {$[0.061]$} & {$[-6.513]$} \\
\hline \multirow[t]{3}{*}{ Disabled x 2009} & -0.052 & -0.063 & 0.012 & -0.105 \\
\hline & $(0.016)$ & $(0.020)$ & $(0.012)$ & $(0.016)$ \\
\hline & {$[-3.187]$} & {$[-3.129]$} & [1.000] & {$[-6.719]$} \\
\hline \multirow[t]{3}{*}{ Disabled x 2010} & -0.020 & -0.132 & -0.012 & -0.111 \\
\hline & $(0.019)$ & $(0.023)$ & $(0.014)$ & $(0.018)$ \\
\hline & {$[-1.084]$} & {$[-5.651]$} & {$[-0.875]$} & {$[-6.222]$} \\
\hline Observations & 94,196 & 105,999 & 124,089 & 137,384 \\
\hline
\end{tabular}

Note: Standard errors are reported in parentheses, $t$-values in square brackets. All regressions include dummies for individual health status, year, age groups, three schooling groups, two race groups, and a full set of year $\mathrm{x}$ health status interactions. 
Table 3: Treatment cases by diagnosis for four demographic groups in 2000

\begin{tabular}{lcccc}
\hline & \multicolumn{3}{c}{ Men } & \multicolumn{2}{c}{ Women } \\
\cline { 2 - 5 } & Age 25-39 & Age 40-58 & Age 25-39 & Ag-58 \\
\hline Infectious diseases & 5.95 & 2.52 & 4.6 & 6.64 \\
Neoplasms & 1.72 & 3.9 & 2.68 & 1.4 \\
Endocrine disorders & 1.98 & 1.42 & 1.94 & 0.87 \\
Diseases of the blood and blood-forming organs & 0.64 & 0.45 & 1.02 & 2.77 \\
Mental disorders & 2.75 & 1.58 & 4.7 & 2.9 \\
Diseases of the nervous system & 2.93 & 2.65 & 8.65 & 21.03 \\
Diseases of the circulatory system & 9.99 & 36.46 & 8.45 & 7.1 \\
Diseases of the respiratory system & 9.58 & 5.58 & 22.37 & 19.06 \\
Diseases of the digestive system & 19.58 & 14.56 & 10.18 & 5.23 \\
Diseases of the genitourinary system & 2.35 & 2.27 & 2.04 & 1.3 \\
Diseases of the skin & 2.89 & 1.29 & 4.38 & 4.71 \\
Diseases of the musculoskeletal system & 5.42 & 4.12 & 0.1 & 0.12 \\
Congenital anomalies & 0.19 & 0.17 & 11.57 & 9.96 \\
Symptoms, signs, and ill-defined conditions & 7.43 & 8.82 & 14.4 & 14.62 \\
Injury and poisoning & 28.71 & 14.22 & & 5,890 \\
\hline Observations & 7,026 & 13,484 & 5,986 \\
\hline
\end{tabular}

Note: percentages are calculated from treatment cases used in the estimation, and are thus restricted to unscheduled and acute hospital admission that last at least three nights, to persons in the relevant age range, who were working and not hospitalized in the previous year. 
Table 4: Summary Statistics by hospitalization status for four demographic groups

\begin{tabular}{|c|c|c|c|c|c|c|c|c|}
\hline & \multicolumn{4}{|c|}{ Age 25-39 } & \multicolumn{4}{|c|}{ Age $40-58$} \\
\hline & \multicolumn{2}{|c|}{2000} & \multicolumn{2}{|c|}{2005} & \multicolumn{2}{|c|}{2000} & \multicolumn{2}{|c|}{2005} \\
\hline & Control & Treatment & Control & Treatment & Control & Treatment & Control & Treatment \\
\hline \multicolumn{9}{|l|}{ Men } \\
\hline Age & 32.16 & 32.78 & 32.31 & 32.99 & 47.98 & 49.50 & 48.15 & 49.74 \\
\hline Native & 0.82 & 0.83 & 0.81 & 0.81 & 0.87 & 0.87 & 0.85 & 0.86 \\
\hline Nonnative Western & 0.08 & 0.08 & 0.08 & 0.08 & 0.09 & 0.09 & 0.09 & 0.08 \\
\hline Nonnative non-Western & 0.09 & 0.09 & 0.11 & 0.11 & 0.04 & 0.04 & 0.06 & 0.06 \\
\hline Married & 0.44 & 0.48 & 0.39 & 0.43 & 0.78 & 0.78 & 0.74 & 0.73 \\
\hline Household size & 2.65 & 2.76 & 2.62 & 2.76 & 3.10 & 2.93 & 3.09 & 2.92 \\
\hline Municipality size & 4.93 & 4.77 & 5.15 & 4.95 & 4.64 & 4.65 & 4.83 & 4.84 \\
\hline Earnings (x 10,000) & 3.53 & 3.43 & 3.45 & 3.37 & 4.66 & 4.30 & 4.61 & 4.25 \\
\hline Observations & $1,452,647$ & 7,026 & $1,231,264$ & 5,172 & $1,373,916$ & 13,484 & $1,345,282$ & 11,511 \\
\hline \multicolumn{9}{|l|}{ Women } \\
\hline Age & 31.80 & 32.16 & 32.09 & 32.39 & 47.37 & 48.32 & 47.78 & 48.82 \\
\hline Native & 0.83 & 0.84 & 0.81 & 0.82 & 0.86 & 0.85 & 0.85 & 0.85 \\
\hline Nonnative Western & 0.09 & 0.08 & 0.09 & 0.09 & 0.10 & 0.10 & 0.09 & 0.09 \\
\hline Nonnative non-Western & 0.07 & 0.08 & 0.09 & 0.09 & 0.04 & 0.05 & 0.05 & 0.06 \\
\hline Married & 0.46 & 0.51 & 0.42 & 0.47 & 0.72 & 0.70 & 0.70 & 0.68 \\
\hline Household size & 2.64 & 2.71 & 2.68 & 2.78 & 2.95 & 2.78 & 3.00 & 2.83 \\
\hline Municipality size & 4.99 & 4.85 & 5.18 & 5.04 & 4.73 & 4.80 & 4.86 & 4.92 \\
\hline Earnings (x 10,000) & 2.27 & 2.24 & 2.32 & 2.19 & 2.15 & 2.10 & 2.25 & 2.15 \\
\hline Observations & $1,029,963$ & 4,890 & 952,582 & 4,269 & 802,039 & 5,986 & $1,044,739$ & 6,959 \\
\hline
\end{tabular}


Table 5: Regression estimates for the probability to receive Disability benefits

\begin{tabular}{lrrrr}
\hline & \multicolumn{3}{c}{ Men } & \multicolumn{2}{c}{ Women } \\
\cline { 2 - 5 } & Age 25 - 39 & Age 40 - 58 & Age 25 - 39 & Age 40 - 58 \\
\hline Effect health shock in 2000 & & & & \\
\multirow{2}{*}{ 1 year later } & & & & \\
& 0.035 & 0.062 & 0.028 & 0.047 \\
& $(0.007)$ & $(0.006)$ & $(0.009)$ & $(0.009)$ \\
years later & {$[4.865]$} & {$[11.099]$} & {$[3.295]$} & {$[5.200]$} \\
& 0.046 & 0.078 & 0.038 & 0.080 \\
3 years later & $(0.009)$ & $(0.008)$ & $(0.014)$ & $(0.016)$ \\
& {$[4.984]$} & {$[9.983]$} & {$[2.818]$} & {$[4.951]$} \\
4 years later & 0.038 & 0.085 & 0.036 & 0.095 \\
& $(0.010)$ & $(0.008)$ & $(0.015)$ & $(0.018)$ \\
& {$[3.880]$} & {$[10.341]$} & {$[2.496]$} & {$[5.423]$} \\
& 0.037 & 0.083 & 0.046 & 0.093 \\
& $(0.010)$ & $(0.009)$ & $(0.016)$ & $(0.018)$ \\
& {$[3.760]$} & {$[9.632]$} & {$[2.962]$} & {$[5.144]$}
\end{tabular}

Effect health shock in 2005 -

effect health shock in 2000

1 year later

2 years later

3 years later
4 years later

$\begin{array}{rrrr}-0.043 & -0.061 & -0.039 & -0.059 \\ (0.003) & (0.002) & (0.004) & (0.005) \\ {[-16.159]} & {[-27.541]} & {[-9.540]} & {[-12.300]} \\ -0.034 & -0.036 & -0.030 & -0.063 \\ (0.004) & (0.004) & (0.007) & (0.008) \\ {[-8.528]} & {[-10.251]} & {[-4.610]} & {[-8.075]} \\ -0.027 & -0.043 & -0.028 & -0.081 \\ (0.004) & (0.004) & (0.007) & (0.009) \\ {[-6.329]} & {[-11.274]} & {[-4.068]} & {[-9.467]} \\ -0.027 & -0.045 & -0.023 & -0.073 \\ (0.004) & (0.004) & (0.007) & (0.009) \\ {[-6.262]} & {[-11.419]} & {[-3.069]} & {[-8.407]}\end{array}$

Note: Standard errors are reported in parentheses, $t$-values in square brackets. The dependent variable is an indicator for DI receipt. All regressions include dummies for five year age groups, nationality, household size, municipality size, province, and labor income from the year prior to the possible health shock (in quartiles), as well as interactions of these variable with an indicator for an unscheduled and acute hospitalization. 
Table 6: Regression estimates for the probability to receive Unemployment benefits

\begin{tabular}{lrrrr}
\hline & \multicolumn{2}{c}{ Men } & \multicolumn{2}{c}{ Women } \\
\cline { 2 - 5 } & Age 25 - 39 & Age 40 - 58 & Age 25 - 39 & Age 40 - 58 \\
\hline Effect health shock in 2000 & & & & \\
& & & & \\
1 year later & 0.015 & 0.013 & 0.005 & 0.007 \\
& $(0.007)$ & $(0.005)$ & $(0.008)$ & $(0.008)$ \\
& {$[2.024]$} & {$[2.611]$} & {$[0.579]$} & {$[0.801]$} \\
years later & 0.015 & 0.017 & 0.027 & -0.001 \\
& $(0.008)$ & $(0.006)$ & $(0.011)$ & $(0.010)$ \\
3 years later & {$[1.754]$} & {$[2.949]$} & {$[2.426]$} & {$[-0.119]$} \\
& 0.011 & 0.019 & 0.016 & -0.011 \\
& $(0.009)$ & $(0.006)$ & $(0.012)$ & $(0.011)$ \\
4 years later & {$[1.149]$} & {$[2.895]$} & {$[1.289]$} & {$[-0.956]$} \\
& 0.021 & 0.023 & 0.013 & -0.004 \\
& $(0.011)$ & $(0.007)$ & $(0.013)$ & $(0.012)$ \\
& {$[1.997]$} & {$[3.235]$} & {$[0.995]$} & {$[-0.339]$}
\end{tabular}

Effect health shock in 2005 effect health shock in 2000

1 year later

2 years later

3 years later

4 years later

\begin{tabular}{rrrr}
-0.003 & -0.007 & -0.011 & -0.016 \\
$(0.003)$ & $(0.002)$ & $(0.005)$ & $(0.004)$ \\
{$[-1.083]$} & {$[-3.246]$} & {$[-2.371]$} & {$[-3.835]$} \\
-0.000 & -0.006 & -0.012 & -0.013 \\
$(0.004)$ & $(0.003)$ & $(0.006)$ & $(0.005)$ \\
{$[-0.106]$} & {$[-2.123]$} & {$[-2.138]$} & {$[-2.709]$} \\
-0.003 & -0.004 & -0.003 & -0.013 \\
$(0.004)$ & $(0.003)$ & $(0.006)$ & $(0.005)$ \\
{$[-0.756]$} & {$[-1.374]$} & {$[-0.534]$} & {$[-1.538]$} \\
-0.001 & -0.002 & -0.004 & -0.004 \\
$(0.005)$ & $(0.003)$ & $(0.007)$ & $(0.006)$ \\
{$[-0.148]$} & {$[-0.564]$} & {$[-0.641]$} & {$[-0.606]$} \\
\hline in parentheses, t-values in square brackets. The
\end{tabular}

Note: Standard errors are reported in parentheses, $t$-values in square brackets. The dependent variable is an indicator for DI receipt. All regressions include dummies for five year age groups, nationality, household size, municipality size, province, and labor income from the year prior to the possible health shock (in quartiles), as well as interactions of these variable with an indicator for an unscheduled and acute hospitalization. 
Table 7: Regression estimates for the probability to receive Social Assistance benefits

\begin{tabular}{ccccc}
\hline & \multicolumn{2}{c}{ Men } & \multicolumn{2}{c}{ Women } \\
\cline { 2 - 5 } Effect health shock in 2000 & & & & \\
\multirow{3}{*}{ 1 year later } & & & & \\
& 0.002 & 0.000 & -0.002 & -0.000 \\
\multirow{3}{*}{ 2 years later } & $(0.002)$ & $(0.001)$ & $(0.002)$ & $(0.001)$ \\
& {$[1.176]$} & {$[-0.139]$} & {$[-0.990]$} & {$[-0.002]$} \\
3 years later & 0.002 & 0.002 & -0.000 & -0.002 \\
& $(0.003)$ & $(0.001)$ & $(0.003)$ & $(0.002)$ \\
& {$[0.632]$} & {$[1.363]$} & {$[-0.018]$} & {$[-1.085]$} \\
4 years later & 0.001 & 0.004 & -0.000 & -0.002 \\
& $(0.003)$ & $(0.002)$ & $(0.004)$ & $(0.002)$ \\
& {$[0.449]$} & {$[2.295]$} & {$[-0.056]$} & {$[-1.055]$} \\
& -0.001 & 0.001 & 0.006 & -0.006 \\
& $(0.004)$ & $(0.002)$ & $(0.004)$ & $(0.003)$ \\
& {$[-0.360]$} & {$[0.781]$} & {$[1.408]$} & {$[-2.192]$}
\end{tabular}

Effect health shock in 2005-

effect health shock in 2000

\begin{tabular}{lcccc}
1 year later & -0.001 & -0.000 & 0.001 & 0.000 \\
& $(0.001)$ & $(0.000)$ & $(0.001)$ & $(0.001)$ \\
2 years later & {$[-1.349]$} & {$[-1.119]$} & {$[1.039]$} & {$[0.271]$} \\
& -0.003 & -0.001 & -0.001 & 0.001 \\
3 years later & $(0.001)$ & $(0.000)$ & $(0.001)$ & $(0.001)$ \\
& {$[-1.996]$} & {$[-1.750]$} & {$[-0.889]$} & {$[1.327]$} \\
4 years later & -0.002 & -0.001 & 0.001 & 0.001 \\
& $(0.002)$ & $(0.001)$ & $(0.002)$ & $(0.001)$ \\
& {$[-1.592]$} & {$[-1.255]$} & {$[0.463]$} & {$[1.089]$} \\
& -0.001 & -0.000 & -0.000 & 0.002 \\
& $(0.002)$ & $(0.001)$ & $(0.002)$ & $(0.001)$ \\
& {$[-0.477]$} & {$[-0.014]$} & {$[-0.250]$} & {$[1.610]$} \\
\hline
\end{tabular}

Note: Standard errors are reported in parentheses, $t$-values in square brackets. The dependent variable is an indicator for DI receipt. All regressions include dummies for five year age groups, nationality, household size, municipality size, province, and labor income from the year prior to the possible health shock (in quartiles), as well as interactions of these variable with an indicator for an unscheduled and acute hospitalization. 
Table 8: Regression estimates for the probability to be employed (= earnings $>20,000$ euro)

\begin{tabular}{|c|c|c|c|c|}
\hline \multirow{2}{*}{\multicolumn{5}{|c|}{ 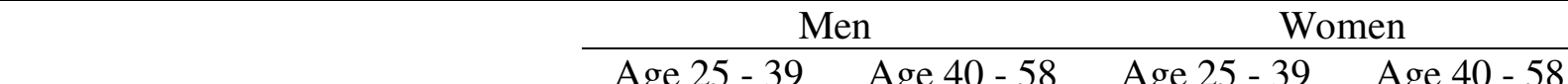 }} \\
\hline & Age $25-39$ & Age $40-58$ & Age $25-39$ & Age $40-58$ \\
\hline \multicolumn{5}{|c|}{ Effect health shock in 2000} \\
\hline \multirow[t]{3}{*}{1 year later } & -0.038 & -0.039 & -0.036 & -0.029 \\
\hline & $(0.012)$ & $(0.008)$ & $(0.019)$ & $(0.018)$ \\
\hline & {$[-3.204]$} & {$[-4.820]$} & {$[-1.863]$} & {$[-1.626]$} \\
\hline \multirow[t]{3}{*}{2 years later } & -0.053 & -0.076 & -0.008 & -0.056 \\
\hline & $(0.014)$ & $(0.010)$ & $(0.023)$ & $(0.021)$ \\
\hline & {$[-3.793]$} & {$[-7.361]$} & {$[-0.364]$} & {$[-2.613]$} \\
\hline \multirow[t]{3}{*}{3 years later } & -0.060 & -0.093 & -0.025 & -0.075 \\
\hline & $(0.015)$ & $(0.012)$ & $(0.025)$ & $(0.023)$ \\
\hline & {$[-4.017]$} & {$[-7.958]$} & {$[-1.005]$} & {$[-3.212]$} \\
\hline \multirow[t]{3}{*}{4 years later } & -0.050 & -0.102 & -0.041 & -0.066 \\
\hline & $(0.016)$ & $(0.012)$ & $(0.027)$ & $(0.024)$ \\
\hline & {$[-3.125]$} & {$[-8.228]$} & {$[-1.542]$} & {$[-2.735]$} \\
\hline \multicolumn{5}{|c|}{$\begin{array}{l}\text { Effect health shock in } 2005 \text { - } \\
\text { effect health shock in } 2000\end{array}$} \\
\hline \multirow[t]{3}{*}{1 year later } & 0.011 & 0.022 & 0.018 & 0.027 \\
\hline & $(0.005)$ & (0.004) & $(0.010)$ & (0.009) \\
\hline & [2.081] & [5.634] & [1.859] & [3.058] \\
\hline \multirow[t]{3}{*}{2 years later } & 0.013 & 0.026 & 0.027 & 0.034 \\
\hline & (0.006) & $(0.005)$ & $(0.011)$ & $(0.011)$ \\
\hline & [2.017] & [5.483] & [2.451] & [3.243] \\
\hline \multirow[t]{3}{*}{3 years later } & 0.024 & 0.028 & 0.032 & 0.039 \\
\hline & $(0.007)$ & $(0.005)$ & $(0.012)$ & $(0.011)$ \\
\hline & [3.464] & [5.225] & [2.631] & [3.459] \\
\hline \multirow[t]{3}{*}{4 years later } & 0.021 & 0.033 & 0.032 & 0.032 \\
\hline & $(0.007)$ & $(0.006)$ & $(0.013)$ & $(0.012)$ \\
\hline & [2.874] & [5.823] & [2.536] & [2.748] \\
\hline
\end{tabular}

Note: Standard errors are reported in parentheses, $t$-values in square brackets. The dependent variable is an indicator for DI receipt. All regressions include dummies for five year age groups, nationality, household size, municipality size, province, and labor income from the year prior to the possible health shock (in quartiles), as well as interactions of these variable with an indicator for an unscheduled and acute hospitalization. 
Table 9: Regression estimates for labor income (x 10,000 euro, in 2010 euros)

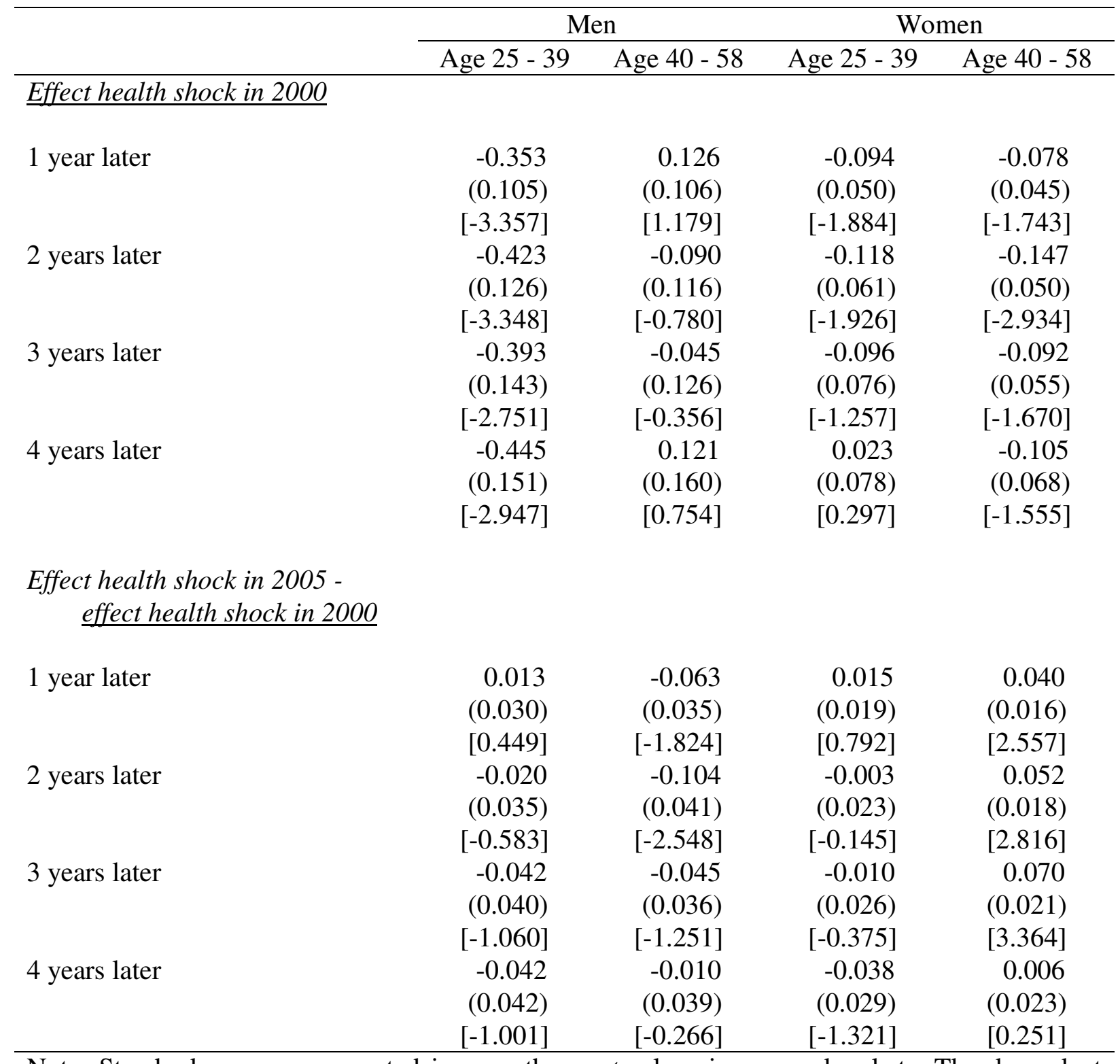

Note: Standard errors are reported in parentheses, $t$-values in square brackets. The dependent variable is an indicator for DI receipt. All regressions include dummies for five year age groups, nationality, household size, municipality size, province, and labor income from the year prior to the possible health shock (in quartiles), as well as interactions of these variable with an indicator for an unscheduled and acute hospitalization. 
Table 10: Regression estimates for the probability to be employed (= earnings $>0$ )

\begin{tabular}{|c|c|c|c|c|}
\hline & \multicolumn{2}{|c|}{ Men } & \multicolumn{2}{|c|}{ Women } \\
\hline & Age $25-39$ & Age $40-58$ & Age $25-39$ & Age $40-58$ \\
\hline \multicolumn{5}{|c|}{$\begin{array}{l}\text { Effect of major health shock in } 2000 \text { - } \\
\text { effect of major health shock in } 2005\end{array}$} \\
\hline \multirow[t]{3}{*}{1 year later } & 0.055 & 0.006 & 0.004 & 0.046 \\
\hline & $(0.032)$ & $(0.009)$ & $(0.082)$ & $(0.035)$ \\
\hline & [1.737] & {$[0.621]$} & {$[0.055]$} & [1.297] \\
\hline \multirow[t]{3}{*}{2 years later } & 0.084 & 0.011 & 0.118 & 0.075 \\
\hline & $(0.036)$ & $(0.011)$ & $(0.089)$ & $(0.037)$ \\
\hline & [2.314] & [0.929] & [1.328] & [2.018] \\
\hline \multirow[t]{3}{*}{3 years later } & 0.086 & 0.009 & 0.170 & 0.114 \\
\hline & $(0.038)$ & $(0.012)$ & $(0.089)$ & $(0.037)$ \\
\hline & [2.236] & [0.759] & [1.896] & [3.085] \\
\hline \multirow[t]{3}{*}{4 years later } & 0.051 & 0.029 & 0.113 & 0.089 \\
\hline & $(0.040)$ & $(0.013)$ & $(0.089)$ & $(0.037)$ \\
\hline & [1.273] & [2.234] & [1.274] & [2.418] \\
\hline \multicolumn{5}{|c|}{ Effect of onset chronic illness in 2005 - } \\
\hline \multirow[t]{3}{*}{1 year later } & 0.011 & 0.043 & 0.029 & 0.031 \\
\hline & $(0.010)$ & $(0.007)$ & $(0.019)$ & $(0.017)$ \\
\hline & [1.029] & [5.923] & [1.498] & [1.843] \\
\hline \multirow[t]{3}{*}{2 years later } & 0.018 & 0.043 & 0.040 & 0.036 \\
\hline & $(0.013)$ & $(0.009)$ & $(0.022)$ & $(0.020)$ \\
\hline & [1.385] & [4.687] & [1.795] & [1.801] \\
\hline \multirow[t]{3}{*}{3 years later } & 0.042 & 0.050 & 0.024 & 0.044 \\
\hline & $(0.014)$ & $(0.010)$ & $(0.024)$ & $(0.044)$ \\
\hline & [3.114] & [4.889] & [0.999] & {$[2.024]$} \\
\hline \multirow[t]{3}{*}{4 years later } & 0.044 & 0.049 & 0.041 & 0.037 \\
\hline & $(0.014)$ & $(0.011)$ & $(0.025)$ & $(0.023)$ \\
\hline & [3.089] & [4.498] & [1.649] & [1.655] \\
\hline \multicolumn{5}{|c|}{$\begin{array}{l}\text { Effect of accident in } 2005 \text { - } \\
\text { effect of accident in } 2000\end{array}$} \\
\hline \multirow[t]{3}{*}{1 year later } & 0.006 & 0.013 & 0.015 & 0.014 \\
\hline & $(0.006)$ & $(0.005)$ & $(0.011)$ & $(0.010)$ \\
\hline & [1.064] & [2.615] & [1.350] & [1.358] \\
\hline \multirow[t]{3}{*}{2 years later } & 0.004 & 0.018 & 0.021 & 0.015 \\
\hline & $(0.007)$ & $(0.006)$ & $(0.013)$ & $(0.012)$ \\
\hline & {$[0.520]$} & [2.900] & [1.605] & [1.198] \\
\hline \multirow[t]{3}{*}{3 years later } & 0.010 & 0.017 & 0.031 & 0.012 \\
\hline & $(0.008)$ & $(0.007)$ & $(0.014)$ & $(0.014)$ \\
\hline & [1.244] & [2.384] & [2.246] & {$[0.851]$} \\
\hline \multirow[t]{3}{*}{4 years later } & 0.007 & 0.019 & 0.027 & 0.008 \\
\hline & $(0.008)$ & $(0.008)$ & $(0.015)$ & $(0.014)$ \\
\hline & [0.896] & [2.485] & [1.844] & [0.564] \\
\hline
\end{tabular}

Note: Standard errors are reported in parentheses, $t$-values in square brackets. The dependent variable is an indicator for employment. All regressions include dummies for five year age groups, nationality, household size, municipality size, province, and labor income from the year prior to the possible health shock (in quartiles), as well as interactions of these variable with an indicator for an unscheduled and acute hospitalization. 
Table 11: Sensitivity analysis of the role of the business cycle on estimated coefficients for the probability to receive Disability benefits and for the probability to be employed

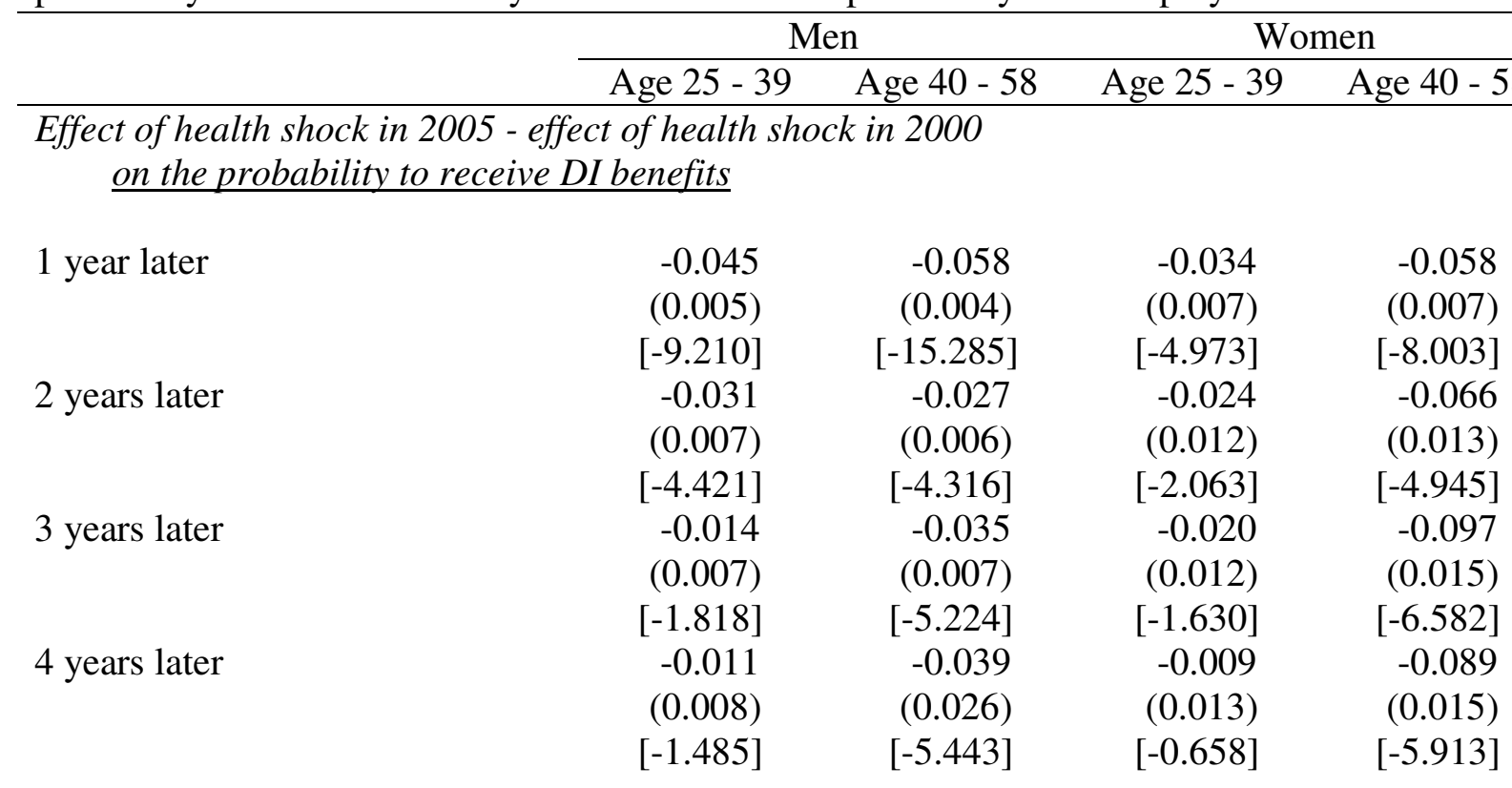

Effect of health shock in 2005 - effect of health shock in 2000 on the probability to be employed

\begin{tabular}{lcccc}
1 year later & 0.016 & 0.015 & 0.026 & 0.019 \\
& $(0.009)$ & $(0.007)$ & $(0.018)$ & $(0.016)$ \\
& {$[1.734]$} & {$[2.123]$} & {$[1.450]$} & {$[1.139]$} \\
2 years later & 0.006 & 0.020 & 0.016 & 0.029 \\
& $(0.011)$ & $(0.009)$ & $(0.021)$ & $(0.019)$ \\
& {$[0.573]$} & {$[2.265]$} & {$[0.749]$} & {$[1.518]$} \\
3 years later & 0.003 & 0.021 & 0.014 & 0.037 \\
& $(0.012)$ & $(0.010)$ & $(0.023)$ & $(0.021)$ \\
4 years later & {$[0.218]$} & {$[2.095]$} & {$[0.616]$} & {$[1.753]$} \\
& -0.001 & 0.028 & 0.015 & 0.044 \\
& $(0.013)$ & $(0.010)$ & $(0.024)$ & $(0.022)$ \\
& {$[-0.083]$} & {$[2.707]$} & {$[0.615]$} & {$[2.033]$} \\
\hline $\begin{array}{l}\text { Note: Standard errors are reported in parentheses, } \\
\text { variable is alues in square brackets. The dependent }\end{array}$ \\
nationality, household size, municipality size, province, and labor income from the year prior to \\
the possible health shock (in quartiles), as well as interactions of these variable with an indicator \\
for an unscheduled and acute hospitalization.
\end{tabular}

